Western University Scholarship@Western

Department of Economics Research Reports

Economics Working Papers Archive

1990

\title{
Money and Growth Revisited
}

Peter Howitt

Follow this and additional works at: https://ir.lib.uwo.ca/economicsresrpt

Part of the Economics Commons

Citation of this paper:

Howitt, Peter. "Money and Growth Revisited." Department of Economics Research Reports, 9014. London, ON: Department of Economics, University of Western Ontario (1990). 
RESEARCH REPORT 9014

MONEY AND GROWTH REVISITED

\author{
by \\ ECONOMICS REFERENGE CERTRE \\ Peter Howitt
}

FEB 272003

UHAVERSTY OF WESTERH DOTARAO

October 1990

\author{
Department of Economics \\ Social Science Centre \\ University of Western Ontario \\ London, Ontario, Canada \\ N6A $5 C 2$
}




\section{MONEY AND GROWTH REVISITED}

\section{by \\ Peter Howitt}

1. The literature on money and growth, in the years following the second edition of Don Patinkin's Money, Interest and Prices, extended the neoclassical monetary theory which Patinkin had systematized and refined, to cover the case of a growing economy, and to investigate not just the neutrality of money but its superneutrality. The main result of this literature (which Patinkin summarized in the introduction to the recently published abridged $2^{\text {nd }}$ edition) is that there is far less reason to believe in superneutrality than in neutrality. Changes in the rate of monetary expansion, by changing the rate of inflation, will ultimately affect the opportunity cost of holding money, and real allocative effects will result from people's responses to this increased cost.

The distinction between neutrality and superneutrality is an important one. The rate of inflation has a significance that cannot be attached to the level of prices. Societies have shown a strong revealed preference for low rates of inflation, by their willingness to incur large costs to achieve a lower rate. In the United States in the 1970s, when the rate of inflation was trivial by comparison with many historical episodes in other countries, often a substantial majority of respondents to the Gallop Poll, sometimes as large as $80 \%$, named inflation as "the most important problem facing the country".1

However, it is doubtful that the nonsuperneutralities uncovered by the money-andgrowth literature are large enough to account for the significance that people attach to inflation. Mundell-Tobin effects ${ }^{2}$ on the steady-state capital stock are commonly estimated to be empirically trivial. And standard triangle measures of the welfare cost of inflation (for 
example, Fischer 1981), which can be shown to be valid in at least some money-and-growth models, imply that the annual cost of having ten percent inflation in the U.S. economy is less than one half of one percent of GNP. Such tiny nonsuperneutralities could never have made inflation a major social problem.

One does not have to look far for reasons why these very simple models might not produce realistic quantitative predictions. Their highly aggregative structure could mask all sorts of problems, especially redistributive ones, that arise from inflation. Their indirect treatment of the role of money in the exchange process could hide others. The absence of uncertainty from the models precludes a detailed analysis of the effects of inflation on people's ability to share risks through limited financial markets.

Some progress has been made in all these directions by research in the past twenty years. But there has yet to emerge a simple paradigm to replace the models developed in the money-and-growth literature. These models still play a prominent role in graduate teaching of monetary economics. The purpose of this essay is to investigate what sorts of changes one might make to a standard money-and-growth model, without destroying its simplicity and tractability, that might allow it to account for empirically significant effects of inflation.

2. This section presents a standard money-and-growth model, which differs from that of Patinkin and Levhari (1968) in three basic respects. First, savings behavior is derived from intertemporal utility maximization by an immortal representative family, as in Sidrauski (1967). Second, instead of inserting real balances into the utility or production function directly, the model specifies a transactions technology in which real balances play the role of reducing transaction costs, as in Dornbusch and Frenkel (1973). Third, positive technological progress is allowed.

At date $t$ the family's preferences are given by:

$$
U_{t}=\int_{l}^{\infty} e^{-\rho(\tau-l)} u(c(\tau)) d \tau
$$


where $c$ is consumption per capita and $\rho$ is a constant, positive rate of time preference. In order to have a nondegenerate steady state with positive technological progress, assume $u($ ) has a constant elasticity of marginal utility equal to $\sigma>0$.

The family produces output at the rate $F(k, A)$ per head, where $k$ is the stock of capital per head and $A$ is a productivity parameter indicating the number of efficiency units of labor each family member possesses. Assume $A$ grows exogenously at the constant proportional rate g. To avoid an unbounded objective function assume $\rho+(\sigma-1) g>0$. The production function $F$ is concave, with positive marginal products. To ensure Harrod-neutrality assume $F$ is homogeneous of degree one.

There are two final uses for output, consumption and investment. In order to put output to final use the family must sell it for money and buy some other family's output, which is otherwise indistinguishable from its own. The activity of trading is costly. Instead of giving an explicit description of how society organizes this activity, the model specifies only the costs it imposes on a family. Specifically, a family that sells at rate $y$, buys at rate $i$ for investment and $c$ for consumption, and holds $m$ in real money balances, must buy additional output at the rate $s$ for use as transaction services, where $s=G(y, i, c, m)$ and all variables are per-capita magnitudes.

The transaction-cost function $G($ ) represents the capital and labor that must be used to shop, to make payments, to manage trade inventories, to conduct retail and wholesale operations, to engage in marketing, advertising, finance and insurance, to search, bargain and set prices, to screen quality, to write, monitor and enforce contracts, and generally to engage in all costly activities that would not be required if the family were not trading its output. Wallis and North (1986) have estimated that transaction services thus defined constitute about 50 percent of measured GNP in the United States. To assume that these activities just use output instead of labor and capital directly is equivalent to assuming that transaction services are produced with the same technology as final output, an assumption that has already been made 
with respect to consumption and investment.

The function $G$ is convex. In order to ensure a well behaved steady state, assume also that $G$ is homogeneous of degree one, despite the many reasons for believing in economies of scale in transacting.

Government plays the limited role of providing fiat money. It does so by making lump-sum transfers to each family member at the real rate $z$ and by paying interest on existing money holdings at the rate $r_{m}$. Thus the family faces the following constraints on its accumulation of capital and money:

$$
k=i-(n+\delta) k
$$

$$
\dot{m}=F(k, A)+z-i-c=G(F(k, A), i, c, m)+\left(r_{m}-\pi-n\right) m
$$

where $n$ is the rate of population growth, $\delta$ the rate of radioactive depreciation, and $\pi$ the rate of inflation. Both $n$ and $\delta$ are exogenous constants. The family chooses the time paths of $k$, $m, i$, and $c$ so as to maximize (1) subject to (2), (3), initial conditions on $k$ and $m$, and non-negativity constraints.

Patinkin and Levhari distinguish between money as a consumer's good and as a producer's good, depending upon whether money enters the utility function or the production function. These can be derived as two special cases of the above analysis, as follows. For the consumer's-good case, suppose that buying for purposes of consumption is the only activity that uses transaction services; that $G_{y}=G_{i}=0, G_{c}>0$. Define $x$ as the gross output devoted to consumption: $x \equiv c+G(c, m)$. This definition can be inverted to yield $c=c(x, m)$. Thus the instantaneous utility function $u$ can be expressed as a function of $x$ and $m: v(x, m) \equiv u(c(x, m))$. The money-accumulation constraint (3) can be re-expressed as:

$$
\dot{m}=F(k, A)+z-i-x+\left(r_{m}-\pi-n\right) m
$$


Thus changing variables from $c$ to $x$ makes the model identical (modulo technical progress) to Sidrauski's. Money now appears in the utility function and there is no explicit transaction-cost function.

For the producer's-good case, assume that selling output is the only costly kind of transaction: $G_{i}=G_{c}=0, G_{y}>0$. Define:

$$
H(k, m, A) \equiv F(k, A)-G(F(k, A), m) .
$$

The constraint (3) can be re-expressed as:

$$
\dot{m}=H(k, m, A)+z-i-c+\left(r_{m}-\pi-n\right) m
$$

With this redefinition there is no explicit transaction-cost function, but money appears as a factor in the "production function" $H()$, which constrains the output available for consumption and investment net of transaction costs.

The only equilibrium condition at each point in time is that the family's choice of $\dot{m}$ must equal the rate at which the government is making the real per-capita money supply expand:

$$
\dot{m}=z+\left(r_{m}-\pi-n\right) m
$$

It follows from (2) (4) that:

$$
k=F(k, A)-(n+\delta) k-c-G(F(k, A), k+(n+\delta) k, c, m) .
$$

Assume the government follows a policy of keeping $\pi$ and $r_{m}$ constant. Given such a policy, and given any initial stock of capital and initial value of the productivity parameter $A$, 
an equilibrium is a time path of $k, m, i, c$ and $z$ which solves the family's utility-maximization problem and the equilibrium condition (4) at each date. ${ }^{3}$ Assume that such an equilibrium always exists and is unique.

Most of the following discussion will focus on steady states: initial values of $k$ and $A$ from which all real per-capita values grow at the constant rate $g$. Assume that given any policy there exists a unique, stable steady-state ray; a vector of productivity-adjusted magnitudes $\left(k^{a}, m^{a}, i^{a}, c^{a}, z^{a}\right)=(k / A, m / A, i / A, c / A, z / A)$. In a steady state the following conditions must hold (see the Appendix for a formal derivation):

$$
\begin{aligned}
\left(1+G_{i}\right)^{-1}\left(1-G_{y}\right) F_{k} & =\rho+\sigma g+n+\delta, \\
-G_{m} & =\rho+\sigma g+n+\pi-r_{m}
\end{aligned}
$$

The term $\rho+\sigma g+n$ on the right side of both conditions is the modified golden-rule rate of interest familiar from optimal growth theory with exogenous technical progress. In a steady state the required return on capital is this rate plus the rate of depreciation. Condition (6) equates this required return to the marginal product of capital net of transaction costs, since the price (in output) of a marginal unit of capital, inclusive of transaction costs, is $\left(I+G_{i}\right)$, and each unit of gross output produced yields $\left(I-G_{y}\right)$ after deducting selling costs. Condition (7) requires the net marginal product of money $\left(-G_{m}\right)$ to equal its opportunity cost (the nominal rate of interest minus the pecuniary yield on money).

3. As Patinkin and Levhari argued, inflation can either raise or lower the steady-state capital stock $\mathrm{k}^{a}$. In the consumer's-good case of Sidrauski the left side of (6) becomes the marginal physical product of capital $F_{k}$, which by homogeneity depends only on the ratio $k / A=k^{a}$. Thus (6) determines $k^{a}$ as a function of the required return, independently of the rate of inflation. 
In the producer's-good case equations (6) and (7) can be written as:

(6') $H_{k}\left(k^{a}, m^{a}, 1\right)=\rho+\sigma g+n+\delta$,

(7') $H_{m}\left(k^{a}, m^{a}, I\right)=\rho+\sigma g+n+\pi-r_{m}$.

These two equations can be solved for $k^{a}$ and $m^{a}$. It follows from the above assumptions on $F$ and $G$ that $H$ is concave and that $m$ and $k$ are complementary factors of production, in the sense that $H_{k m}>0$. With these results, routine comparative-statics analysis shows $\partial k^{a} / \partial \pi<0$. More inflation will raise the opportunity cost of holding money, which will induce a smaller holding of it and of the complementary factor capital.

The Mundell-Tobin result that inflation raises the steady-state capital stock is not ruled out by the analysis. However, if it arises it does so for reasons having to do with the effects of money holdings on the marginal costs of different kinds of transactions, rather than the effects on the propensity to save.

In order to approximate the magnitude of the effect of inflation on steady-state capital, consider the producer's-good case. Assume that $H$ is Cobb Douglas: $H=k^{\alpha} m^{\beta}{ }^{l-\alpha-\beta}$. From $\left(6^{\prime}\right)$ and $\left(7^{\prime}\right)$ :

$$
\frac{1}{k} \frac{\partial k^{a}}{\partial \pi}=\frac{-m^{a}}{(1-\alpha-\beta) H\left(k^{a}, m^{a}, 1\right)}
$$

Suppose $(1-\alpha-\beta)=.7$, and that, as a ratio to GNP per capita, $H(k, m, A)$ is one half and $m$ is one seventh. These number are chosen to approximate their values in the United States economy in the $1980 \mathrm{~s},{ }^{4}$ with money interpreted as the non-interest bearing component, M1. Then: 


$$
\frac{1}{k^{a}} \frac{\partial k^{a}}{\partial \pi}=-0.41
$$

That is, a one point rise in the annual rate of inflation will cause the steady-state capital stock to decline by four tenths of a percent. This is perhaps not trivial, but it is far from the magnitude that could explain the importance people attach to inflation.

4. To calculate the welfare cost of inflation, behavior out of the steady state must be considered. The effect of inflation on the lifetime utility of the representative family is:

$$
\partial U_{\delta} \partial \pi=\int_{0}^{\infty} e^{-\rho t} u^{\prime}\left(c^{e}\right)\left(\partial c^{e} / \partial \pi\right) d t
$$

where the superscript $e$ denotes the equilibrium value, as a function of time, the rate of inflation, and the initial conditions. Since the equilibrium must satisfy the resource constraint (5), it follows that:

$$
\partial U_{\delta^{\prime}} \partial \pi=\int_{0}^{\infty} e^{-\rho t} u^{\prime}\left(c^{e}\right)\left(1+G_{c}\right)^{-1}\left[\left(1-G_{y}\right) F_{k} \frac{\partial k^{e}}{\partial \pi}-\left(1+G_{i}\right) \frac{\partial i^{e}}{\partial \pi}-G_{m} \frac{\partial m^{e}}{\partial \pi}\right] d t .
$$

By a version of the envelope theorem (see Appendix) the terms in $\frac{\partial k^{e}}{\partial \pi}$ and $\frac{\partial i^{e}}{\partial \pi}$ vanish; thus:

$$
\partial U_{0} \partial \pi=-\int_{0}^{\infty} e^{-\rho t} u^{\prime}\left(c^{e}\right)\left(1+G_{c}\right)^{-1} G_{m} \frac{\partial m^{e}}{\partial \pi} d t
$$

To interpret this expression, note that $u^{\prime}\left(c^{e}\right)\left(1+G_{c}\right)^{-1}$ is the shadow value $\lambda_{m}$ of money; the utility of receiving a marginal unit of $m$, because one unit of $m$ buys $\left(I+G_{c}\right)^{-1}$ units of consumption net of transaction costs. Assume that the equilibrium being perturbed by 
the change in $\pi$ is a steady state. Then $\lambda_{m}$ falls steadily at the exponential rate $\sigma g$. So the marginal welfare cost of inflation is:

$$
-\frac{\partial U_{0} / \partial \pi}{\lambda_{m}(0)}=-\int_{0}^{\infty} e^{-(r-\pi-n) t}\left(r-r_{m}\right) \frac{\partial m^{e}}{\partial \pi} d t
$$

where $r-\pi$ is the modified golden-rule rate of interest: $\rho+\sigma g+n$, and where (7) has been used to eliminate $-G_{m}$.

Expression (8) would be the usual welfare-cost measure if $m^{e}$ were a demand function for money instead of the function describing the equilibrium. To be more precise, the expression $\partial m^{e} / \partial \pi$ does not represent the effect on the demand for $m$ from a marginal change in the opportunity cost $r-r_{m}$ with no change in the scale variable(s) in a demand function for money. Thus (8) does not correspond exactly to the usual measure.

Nevertheless the magnitude of (8) is about as small as the usual measure. In the consumer's-good case it is exactly the same, as the following analysis shows. The steady-state condition (7) can be expressed as:

$$
-G_{m}(c(x, m), m)=r-r_{m}
$$

If the economy begins in a steady state, then $m^{e}=m^{d}\left(x, r-r_{m}\right)$, where $m^{d}()$ is the demand function implicitly defined by this condition. A rise in inflation would leave the economy in a steady state, with the course of $k$ unchanged. From (5) and the definition of $x$ :

$$
x=F(k, A)-(n+\delta) k-k
$$

therefore the course of $x$ would also be unchanged. Since $r-r_{m}$ would rise point-for-point with $\pi$, therefore $\partial m^{e} / \partial \pi=\partial m^{d} / \partial\left(r-r_{m}\right)$. 
5. One obvious reason for the small effects of inflation in the above model is that they all operate through the opportunity cost of holding the non-interest-bearing component of money, 5 which constitutes a small fraction of national wealth. In the United States in 1987, M1 was one seventh of GNP. Even with a ten percent annual discount rate this would make M1 only one seventieth of total wealth. It is hard to believe that a tax on this small item is what makes inflation such an important social problem.

Thus it seems natural to explore effects of inflation that work through channels other than the opportunity cost of holding cash. As Mussa (1977) has argued, there are such channels, and they depend upon money's roles as unit of account and standard of deferred payment. One important class of examples arises from the almost universal absence of indexation clauses in debt contracts. Because of this, higher inflation creates liquidity problems by front-end-loading conventional debt instruments. It also makes it harder for people to share risks efficiently when inflation rises, if higher inflation is also more uncertain inflation, which seems to be the case, at least in the postwar period (see Fischer, 1981).

Another class of examples arises from society's inability to keep business and government accounts in real terms. This introduces well-known distortions into the corporate and personal income tax systems, even when they have been indexed for bracket creep. These distortions affect different industries and different classes of investment differently, and thus affect the pattern of resource allocation across industries and classes of capital goods. The increasing distortion of corporate and government balance sheets and income statements also inhibits rational decision making.

Another example is the effect of inflation-uncertainty on the duration of wage contracts. More frequent wage negotiations are induced by the increasing riskiness of long-term contracts. Beyond the direct negotiation costs this raises the incidence of potentially disruptive conflicts between labor and management.

Because many prices are quoted in units of money, and changed only periodically, higher inflation tends to induce more frequent prices changes, and hence to raise "menu costs". 
More importantly, it is also likely to increase the dispersion of prices around the values they would have taken in the absence of expected inflation. This distorts the trading decisions of the individuals who take those prices as given. It may induce a waste of resources in the form of more extensive search for lower prices. By making price information obsolete more rapidly it also may increase uncertainty, thereby reducing ex ante welfare.

One feature shared by all these effects is that they make it more difficult for people to trade at any given level even if real holdings of money and other liquid assets are unchanged. Accordingly, they may be referred to collectively as the transaction-impeding aspect of inflation. In contrast, the effects that work through the opportunity cost of holding cash may be referred to as the money-taxing aspect, because they operate only to the extent that inflation is seen as a marginal tax on the holding of cash.

Many of the above-cited examples of the transaction-impeding aspect are difficult to incorporate explicitly into a simple framework. But they can all be incorporated indirectly by making the transaction-cost function depend upon the rate of inflation. This indirect treatment mirrors the standard treatment given above to the role of money in the transactions process. Although it is not very illuminating about details, it does at least allow straightforward treatment of general effects. Accordingly, suppose that the transaction-cost function can be written as $G(y, i, c, m, \pi)$, which is homogeneous of degree one in $(y, i, c, m)$ and convex.

Another feature shared by all the above-cited examples of the transaction-impeding aspect is that they tend to make deflation costly as well as inflation. Deflation-neutral accounting poses exactly the same problems as inflation-neutral accounting. Menu costs and the associated difficulties would be increased as much by deflation as by inflation. To the extent that the positive correlation between the level of inflation and its variability arises because of the inherently uncoordinated nature of a process in which people try to adjust nominal prices to keep up with each others' nominal prices, it would be reversed under deflation, which would pose symmetrical coordination problems. To recognize this general feature of the transaction-impeding aspect, assume that $G_{\pi} \gtreqless 0$ as $\pi \gtreqless 0$. 
Making this change in $G$ to recognize the transaction-impeding aspect of inflation has little effect on the formal structure of the model. The same conditions characterize equilibrium as before. Note, however, that in the consumer's-good case the derived utility function now depends negatively on inflation (if $\pi$ is positive, which is assumed henceforth except when stated otherwise) because $x=c+G(c, m, \pi)$. Likewise for the net production function in the producer's-good case: $H(k, m, A, \pi) \equiv F(k, A)-G(F(k, A), m, \pi)$.

The effect of inflation on the steady-state capital stock is again ambiguous. In the consumer's-good case the effect is zero, for the same reason as before. In the producer's-good case the effect is again negative.

However, the transaction-impeding aspect strengthens the negative effect in the producer's-good case. As before, inflation reduces the long-run capital stock by reducing the net marginal product of any given stock, and thus inducing people to save less. But now the effect on productivity works not just through taxing the holding of the complementary factor money but also directly through the transaction-impeding aspect.

More formally, from $\left(6^{\prime}\right)$ and $\left(7^{\prime}\right)$ :

$$
\frac{\partial k^{a}}{\partial \pi}=-\Delta^{-1} H_{k m}+\Delta^{-1}\left(H_{m \pi} H_{k m}-H_{k \pi} H_{m m}\right)
$$

where $\Delta$ is the Jacobian determinant. Putting $\pi$ into $G()$ adds the second term, which is negative. 6

The transaction-impeding aspect of inflation also tends to increase the marginal welfare cost of inflation. Starting from a steady state the cost is

$$
-\frac{\partial U_{0} / \partial \pi}{\lambda_{m}(0)}=\int_{0}^{\infty} e^{-(r-\pi-n) t}\left[-\left(r-r_{m}\right)\left(\partial m^{e} / \partial \pi\right)+G_{\pi}\right] d t
$$


which adds the additional term $G_{\pi}$ to (8). In the consumer's-good case, where the usual triangle measure used to be valid, the true cost now exceeds the usual measure.

The transaction-impeding aspect makes the marginal welfare cost positive even when the Friedman rule: $r-r_{m}=0$ is followed. The welfare-maximizing policy is to follow the Friedman rule and also set $\pi=0$, which would make the marginal welfare loss (9) equal to zero. This generally requires both instruments to be used, in contrast to the usual case where either $\pi$ or $r_{m}$ could be used to achieve optimality. If interest cannot be paid on money the second-best policy is to set $\pi$ somewhere between zero and the Friedman rate of $-(\rho+\sigma g+n) .^{7}$

6. Another obvious shortcoming of the standard money-and-growth model is that it takes the rate of technological progress $g$ as exogenous. (The standard treatment in the money-andgrowth literature is in fact to assume $g=0$.) As in the standard Ramsey-Solow model, this makes the economy's long-run growth rate $(n+g)$ independent of almost all economic factors, including the rate of inflation. But there is reason to think that inflation has a sustained, negative effect on growth.

More specifically, a rise in inflation takes resources out of producing final output and draws them into producing transaction services. This phenomenon has been noticed by many observers of high inflation countries, ${ }^{8}$ and some think it is also manifested by the high salaries that drew young people to Wall Street in the 1980s. It is also implied by the model of the previous section in the producer's-good case. ${ }^{9}$ Most of the obvious sources of long-run technological change also use real resources, in the form of research and development, the accumulation of human and organizational capital, and learning by doing. If inflation draws resources out of producing final output, then for the same reasons it is likely to draw them out of these activities that underlie technological change. As Leijonhufvud has emphasized (1981, pp. 247-9) inflation is likely to divert managers' efforts away from creating new products, processes and markets, and towards finding ways to deal with inflation-induced tax 
complications, devising new financial contracts, and forecasting the course of the price level. The effect is likely to be a decrease in the rate of technological change, and hence in the economy's growth rate.

These considerations can be incorporated into the model of the previous section using the following simple variant of Uzawa's (1965) model of endogenous growth. Specifically, suppose that in addition to consuming, investing, hoarding and transacting, the representative family can use output to make $A$ grow, according to the constraint:

$$
\dot{A}=i^{A}-n A,
$$

where $i^{A}$ is the amount of output put into research, development, education, and so on. Equation (10) assumes that the process of technology growth uses resources in the same proportions as consumption, investment, and transaction services. The family maximizes utility subject to (2), (3) and (10), with (3) now modified by adding the term $-i^{A}$ to the right side.

To simplify the analysis, from here on assume the producer's-good case. A necessary condition for the family to be investing in capital and making technology grow simultaneously at positive rates is that the net marginal products of $k$ and $A$ be equal:

$$
F_{k}(k, A)\left(I-G_{y}\right)-\delta=F_{A}(k, A)\left(I-G_{y}\right)
$$

To simplify further assume no depreciation. Then the above condition implies equalization of the gross marginal products: $F_{k}=F_{A}$. Since $F$ is homogeneous of degree one this implies that $(k / A)$ must assume a unique value $\hat{k}^{a}$ which depends only upon the production function $F$.

The final simplifying assumption is that the economy is initially in a steady state, with $k / A=\hat{k}^{a}$. Changes in monetary policy will leave that ratio unchanged, so the model can aggregate over $k$ and $A$. Let $K$ denote the number of bundles of "aggregate capital", each 
containing $1 /\left(I+\hat{k}^{a}\right)$ units of "knowledge capital" $(A)$ and $\hat{k}^{a} /\left(I+\hat{k}^{a}\right)$ units of "physical capital" (k). Since $F$ exhibits constant returns in $k$ and $A$, it can be written as: $y=a K$. The net production function becomes:

$$
H(K, m, \pi) \equiv a K \cdot G(a K, m, \pi) .
$$

With the model thus reformulated the conditions (6) and (7) reappear as:

(6") $\quad H_{k}(1, \lambda, \pi)=\rho+\sigma g+n$,

$$
\text { (7") } \quad H_{m}(1, \lambda, \pi)=\rho+\sigma g+n+\pi-r_{m} \text {, }
$$

where $\lambda \equiv m / K$ is the money/"capital" ratio. These conditions can be derived exactly as before, and have the same interpretation. Homogeneity now allows the marginal products to depend only on the ratio $\lambda$. However, $g$ is no longer exogenous. Furthermore, the conditions must hold at each point in time, not just in the long run, because even an unexpected change in inflation requires no change in the ratio of physical to knowledge capital. The two equations can be solved for $\lambda$ and $g$. As long as $K, m$ and $c$ continue to grow at the constant rate $g$ the equations will continue to be satisfied until disturbed again. 10

An increase in inflation will reduce the growth rate. Intuitively, the same forces through which inflation reduced the net marginal product of capital in the previous section are at work again. But instead of reducing the ratio of $k$ to $A$ they induce people to make both $k$ and $A$ grow more slowly. What equilibrates the system is the fall in $g$. As people anticipate a slower rise in consumption, and hence a slower decline in the marginal utility of consumption, the rate of interest $(\rho+\sigma g+n)$ falls, as it would in a simple Fisherine two-period analysis if everyone's expectation of future endowments fell. The long-run negative effect of inflation on the real rate of interest is consistent with a lot of empirical evidence drawn from U.S. data (see Fried and Howitt, 1983 for a brief survey). 


\section{Formally, 11}

$$
\partial g / \partial \pi=-\left(\lambda+G_{\pi}\right) / \sigma(I+\lambda)<0, \quad \partial(r-\pi) / \partial \pi=-\left(\lambda+G_{\pi}\right) /(I+\lambda)<0 .
$$

Note that these effects would be negative without the transaction-impeding aspect (if $\boldsymbol{G}_{\boldsymbol{\pi}}$ were zero). However, without the transaction-impeding aspect the effect of inflation on the real rate of interest would be very small, since $\lambda(1+\lambda)$ is the share of non-interest bearing money in national wealth. The effect on growth would probably also be small without the transaction-impending aspect, although it is hard to make any definite statements given the extreme variability of empirical estimates of $\sigma .12$

To calculate the marginal welfare cost of inflation, note that $c^{e}(t)=c^{e}(0) e^{g t}$. So:

$$
\partial c^{e}(t) / \partial \pi=e^{g t}\left(\partial c^{e}(0) / \partial \pi+t c^{e}(0) \partial g / \partial \pi\right)
$$

Using this and the fact that, from the appropriately modified version of (5):

$$
c^{e}(0)=K_{0} H(1, \lambda, \pi)-(n+g) K_{0}
$$

the Appendix shows that:

$$
\begin{aligned}
&-\frac{\partial U_{0} / \partial \pi}{\lambda_{m}(0)}=\frac{-\left(r-r_{m}\right)\left(\partial m^{e}(0) / \partial \pi\right)+G_{\pi}\left(a K_{0}, m^{e}(0), \pi\right)}{r-\pi-n-g} \\
&-\frac{(\partial g / \partial \pi) m^{e}(0)\left(r-r_{m}\right)}{(r-\pi-n-g)^{2}}
\end{aligned}
$$

where $\partial m^{e}(0) / \partial \pi=K_{0} \partial \lambda / \partial \pi$.

The first term in (12) is the same as the marginal welfare loss (9) when technological growth is exogenous. The integral in (9) can be solved in the present case because $\partial m^{e}(t) / \partial \pi$ grows at the constant rate $g$. Endogenizing technological change thus increases the cost by 
adding the second term.

This extra cost can be interpreted as the present discounted cost of making the usual triangle grow more rapidly. Note that it is dependent on the money-taxing aspect of inflation; that is, it would go away if the money-taxing aspect were eliminated by imposing the Friedman rule of $r-r_{m}=0$. Since it is proportional to $m^{e}(0)$, one might be tempted to dismiss it as no more significant empirically than the usual triangle measure. However, the fact that it is discounted by the square of the rate at which the marginal triangle is discounted could offset that. Intuitively, making even a very small cost grow more rapidly can have a large effect on the present value of the cost if the discount rate is small. Note that the transaction-impeding aspect may be required to make the extra cost empirically significant, because without it the small $m^{e}(0)$ would be multiplied by the term $\partial g / \partial \pi$, which is also likely to be small without the transaction-impeding aspect.

7. One final way in which the above account could be improved is by recognizing externalities. Two important externalities suggest themselves immediately. The first is the spillover likely to be present in the accumulation of knowledge capital. As has long been recognized, not all of the gains from research and development can be captured by their creators. Similarly for knowledge created from learning by doing. As Lucas (1988) has emphasized, there are also positive externalities associated with human capital, of which the advantage of having stimulating colleagues is only one example.

Now there may also be important negative spillovers in some aspects of the research and development process. Additions to knowledge typically steal rents from competitors as well as adding to the social product. However, it appears to be the judgment of those who have studied the research and development process most thoroughly (for example, Griliches, 1979, p. 99) that positive spillovers are the dominant ones.

Technology spillover tends to make the economy's growth rate less than optimal. If inflation reduces growth, then the fact that it is too low to begin with will magnify the 
marginal welfare cost. Furthermore, Romer (1986) has shown how the analysis of learning by doing started by Kaldor and Arrow can be formalized to incorporate technology spillover into the kind of framework used here (although without money). ${ }^{13}$

Suppose, accordingly, that the family's production function can be written as $y=F(K, \bar{K})$, where $\bar{K}$ is the average amount of aggregate capital per head possessed by other families in the economy, and where $F$ is concave and homogeneous of degree one, with $F_{K}>$ 0 and $F_{\bar{K}}>0$. This formulation allows the family to benefit from others' knowledge, which is part of $\bar{K}$. The net production function becomes:

$$
H(K, \bar{K}, m ; \pi) \equiv F(K, \bar{K})-G(F(K, \bar{K}), m, \pi)
$$

In steady-state equilibrium each family must again satisfy the optimality conditions:

$$
\begin{aligned}
& H_{K}(K, \bar{K}, m, \pi)=\rho+\sigma g+n, \\
& H_{m}(K, \bar{K}, m, \pi)=\rho+\sigma g+n+\pi-r_{m} .
\end{aligned}
$$

Since all families are identical each may be assumed to have the same $K$ in equilibrium: $K=\vec{K}$. This allows the above conditions to be simplified as follows.

Because $F$ has constant returns, therefore $F(K, K)=a K$, where $a$ is the (constant) marginal social product of capital. Define the marginal private product as $a_{1}=F_{K}(K, K)$. By homogeneity $a_{1}$ is independent of $K$. Because of the positive spillover $a_{1}<a$. Using these definitions and substituting $K=\bar{K}$ in the above optimality conditions yields:

$$
\begin{aligned}
a_{1}\left(1-G_{y}(a, \lambda, \pi)\right) & =\rho+\sigma g+n, \\
-G_{m}(a, \lambda, \pi) & =\rho+\sigma g+n+\pi-r_{m},
\end{aligned}
$$

where again $\lambda \equiv m / K$. 
As before, the economy goes immediately to the steady state defined by these equations. Because $a_{1}<a$, technology spillover reduces the growth rate. Also:

$$
\partial g / \partial \pi=-\left(\lambda+G_{\pi}\right) / \sigma\left(a / a_{1}+\lambda\right)<0
$$

which shows a weaker effect of inflation on growth than the effect (11) that would occur without the spillover, because $a_{1}<a$.

The marginal welfare cost of inflation can be derived as in the previous section. The result is:

$$
\begin{aligned}
-\frac{\partial U_{0} / \partial \pi}{\lambda_{m}(0)}= & \frac{-\left(r-r_{m}\right)\left(\partial m^{e}(0) / \partial \pi\right)+G_{\pi}}{r-\pi-n-g} \\
& -\frac{(\partial g / \partial \pi)\left[m^{e}(0)\left(r-r_{m}\right)+K F_{K}(K, K)\left(1-G_{y}\right)\right]}{(r-\pi-n-g)^{2}}
\end{aligned}
$$

Thus technology spillover increases the cost by adding the term in $K F_{R}\left(I-G_{y}\right)$. This additional term is potentially very large, because it is not limited by the size of real cash balances, and its denominator is the square of the net discount rate. Again, however, the empirical significance of the effect may depend on the transaction-impeding aspect, without which $\partial g / \partial \pi$ would probably be small.

The other externality that suggests itself immediately is the thin-market externality of Diamond (1984). One person's decision to trade more actively makes it easier for potential trading partners to buy and sell. The thin-market externality could be incorporated by writing the transaction-cost function as $G(y, \bar{y}, m, \pi)$, where $\bar{y}$ is the amount produced on average by other families, with $G$ homogeneous of degree one in $(y, \bar{y}, m)$ and convex, and $G_{\bar{y}}<0$. In this case the fact that $G$ has constant returns in three arguments rather than two makes 
comparative-statics analysis ambiguous. But under the additional assumptions that $G_{y m}<0$ and $G_{m m} G_{y \pi}-G_{y m} G_{m \pi}>0$ it can be shown that the thin-market externality adds to the marginal welfare cost just as technology spillover does.

8. Until this point in the argument the instruments of monetary policy have been the rate of interest on money and the rate of inflation. While this has been convenient, it has precluded addressing the superneutrality issue raised at the beginning of the essay, which concerns the the consequences of exogenous variations in the rate of monetary expansion: $\mu \equiv r_{m}+z / m$, because it has made $\mu$ (implicitly) an endogenous variable. This section takes $\mu$ and $r_{m}$ as the policy instruments and briefly addresses the question of superneutrality.

Equilibrium is now a time path for $k, m, i, c, z$ and $\pi$ such that the same utility-maximization problem is solved as before, the same equilibrium condition (4) holds, and at each date $z=\left(\mu-r_{m}\right) m$. A steady-state equilibrium is characterized by the same conditions as before, and in addition:

$\pi=\mu-n-g$,

which follows from (4), the definition of $\mu$, and the steady-state condition: $\dot{m} / m=g$.

The consequences of varying the rate of monetary expansion are made hard to predict by the possibility of multiple equilibria. Speculative bubbles and indeterminacy (a steady state which is approached by a continuum of distinct trajectories) cannot easily be ruled out as perfect foresight equilibria, not to mention stationary sunspot equilibria in which rationally expected price-level fluctuations occur in response to an extrinsic random variable.

If these multiplicities are ruled out as before by assuming a unique, stable steady state, then the consequences of varying $\mu$ are almost the same as those of varying $\pi$ in the above analysis. Thus the factors that were introduced into the standard model above; namely the transaction-impeding aspect of inflation, endogenous growth of technology, and externalities, 
will amplify the nonsuperneutralities of the standard model just as they have amplified the costs and consequences of inflation.

Two additional comments are in order regarding multiplicity of equilibria and the endogenous growth of technology. First, assuming a unique, stable steady state requires more than ruling out bubbles, sunspots and indeterminacy. It also requires ruling out the situation depicted in Figure 1 below, where multiple steady-state growth rates and rates of inflation exist for the same rate of monetary expansion.

\section{PLACE FIGURE 1 HERE}

The curve labeled $g(\pi)$ in Figure 1 depicts the equilibrium growth rate as a function of $\pi$ in the endogenous-growth model of section 6 . To simplify the analysis suppose that the government always varies $r_{m}$ so as to hold constant the real rate of interest paid on money $r_{m}-\pi$. This means that only the transaction-impeding aspect of inflation is affecting growth. From (6") and ( $\left.7^{\prime \prime}\right)$ the slope of the equilibrium locus is: 14

$$
g^{\prime}(\pi)=\partial g / \partial \pi+\partial g / \partial r_{m}=-G_{\pi} / \sigma(1+\lambda)
$$

As indicated in Figure 1, the equilibrium locus reaches a maximum at $\pi=0$. Also, (6") implies that the locus has a lower bound $(q \equiv-(\rho+n) / \sigma)$ as long as $1-G_{y}$ is always positive; that is, as long as it is always possible to increase net output by producing more, which is now assumed.

The straight line with slope -1 depicts the equilibrium rate of inflation (15) as a function of $g$. Steady states exist where the two curves intersect. Thus at least three equilibria will exist for some values of $\mu$ if there is some $\pi$ such that $g^{\prime}(\pi)<-1$, as shown by point $B$. It is straightforward to construct such examples. 15 
Thus the expectation of high inflation can be self-fulfilling even if bubbles, sunspots and indeterminacy are ruled out. The reduction in growth it produces can validate the expectation with no change in the rate of monetary expansion. The consequences for superneutrality are twofold. First, the analysis yields one more reason why it is difficult to predict the consequences of a change in monetary expansion; the change could result in the selection of a different equilibrium. Second, small changes in monetary expansion could produce very large changes in inflation and growth. For example, as $\mu$ is increased in Figure 1 to the point where $A$ and $B$ come together, any slight further increase in $\mu$ will cause these equilibria to vanish. If the economy had been in $A$, the slight change will drive it to $C$, with a large rise in inflation and a large fall in growth.

The other comment on multiplicity arises from the work of Stadler (1986), who has pointed out that endogenous technological growth generally destroys not just superneutrality but also long-run neutrality. There are many reasons for believing in short-run nonneutrality (all of which are absent from the present analysis). Changes in the money supply have at least temporary effects on the level of economic activity. Stadler argues that these effects also imply temporary variations in the learning and research activities that underlie technological growth. Even if in the long run these activities return to normal, the extra knowledge created by a temporary increase will last forever. Thus a once-over change in the money supply has permanent real effects.

This implies that endogenous technological growth has consequences for neo-classical monetary theory that go beyond the superneutrality issues addressed here. It also implies that the same considerations which magnify the gains from achieving a lower rate of inflation may also magnify the costs. As with other well-known examples of hysteresis, Stadler's nonneutrality implies that the cost of using restrictive monetary policy to reduce inflation is magnified in present value by its permanence. 
9. The paper has shown that modifying a standard money-and-growth model to incorporate the transaction-impeding aspect of inflation, endogenous growth of technology, and externalities, can magnify the model's nonsuperneutralities. These modifications also add two new long-run effects of monetary expansion; a negative effect on the rate of economic growth and a negative effect on the real rate of interest even when the rate of time preference is constant. Finally, they open up the possibility of a new kind of multiplicity of equilibria; given the same rate of monetary expansion there may be multiple steady states, across which higher inflation accompanies lower economic growth. Although much work remains to be done before the empirical significance of these new nonsuperneutralities can be assessed, they are not limited by the small size of money in proportion to national wealth as long as the transaction-impeding aspect of inflation is present. 


\section{Beferences}

Diamond, Peter, A Search-Equilibrium Approach to the Micro Foundations of Macroeconomics, Cambridge, MA: MIT Press, 1984.

Dornbusch, Rudiger, and Jacob Frenkel, "Inflation and Growth: Alternative Approaches," Journal of Money, Credit and Banking, February 1973, 5, 141-56.

Fischer, Stanley, "Toward an Understanding of the Costs of Inflation: II," in Karl Brunner and Allan Meltzer, eds., The Costs and Consequences of Inflation, Carnegie-Rochester Conference Series on Public Policy, 1981, Vol. 15, 5-42. and John Huizinga, "Inflation, Unemployment and Public Opinion Polls," Journal of Money, Credit and Banking, February 1982, 14, 1-19.

Fried, Joel and Peter Howitt, "The Effects of Inflation on Real Interest Rates," American Economic Review, December 1983, 73, 968-80.

Griliches, Zvi, "Issues in Assessing the Contribution of Research and Development to Productivity Growth," Bell Journal of Economics, Spring 1979, 10, 92-116.

Kleiman, Ephraim, "The Costs of Inflation," Hebrew University Working Paper, May 1989.

Konieczny, Jerzy, "On the Role of Money as a Unit of Account and the Welfare Cost of Inflation," Unpublished, Wilfrid Laurier University, 1987.

Leijonhufvud, Axel, "Costs and Consequences of Inflation," in his Information and Coordination: Essays in Macroeconomic Theory, New York, Oxford University Press, 1981.

Lucas, Robert E. Jr., "On the Mechanics of Economic Development," Journal of Monetary Economics, July 1988, 22, 3-42.

Mehra, Rajnish and Edward Prescott, "The Equity Premium: A Puzzle," Journal of Monetary Economics, March 1985, 15, 145-161.

Mitsui, Toshihide and Shinichi Watanabe, "Monetary Growth in a Tumpike Environment," Journal of Monetary Economics, July 1989, 24, 123-37. 
Mundell, Robert, "Inflation and Real Interest," Journal of Political Economy, June 1963, $71,280-83$.

Mussa, Michael, "The Welfare Cost of Inflation and the Role of Money as a Unit of Account," Journal of Money, Credit and Banking, May 1977, 9, 276-86.

Patinkin, Don, Money, Interest and Prices, 2nd ed., abridged, Cambridge, MA: MIT Press, 1989. , and David Levhari, "The Role of Money in a Simple Growth Model," American Economic Review, September 1968, 58, 713-53.

Romer, Paul, "Increasing Returns and Long-Run Growth," Journal of Political Economy, October 1986, 94, 1002-37. , "Endogenous Technological Change," Journal of Political Economy, 1990, forthcoming.

Sidrauski, Miguel, "Rational Choice and Patterns of Growth in a Monetary Economy," American Economic Review Proceedings, May 1967, 57, 534-44.

Stadler, George, "Real Versus Monetary Business Cycle Theory and the Statistical Characteristics of Output Fluctuations," Economic Letters, 1986, 22, 51-4.

Tobin, James, "Money and Economic Growth," Econometrica, October 1965, 33, 671-84.

Uzawa, Hirofumi, "Optimal Technical Change in an Aggregative Model of Economic Growth," International Economic Review, January 1965, 6, 18-31.

Wallis, John, and Douglas North, "Measuring the Transaction Sector in the American Economy, 1870-1970," in Stanley Engerman and Robert Gallman, eds., Long-Term Factors in American Economic Growth, Chicago: University of Chicago Press, 1986. 


\section{Appendix}

The decision problem of section 2 is a standard discounted optimal-control problem with an undiscounted Hamiltonian:

$$
\begin{aligned}
& H^{*}\left(c, i, m, k, t, \lambda_{m}, \lambda_{k}\right) \\
& \equiv u(c)+\lambda_{m}\left[F(k, A)+z-i-c-G(F(k, A), i, c, m)+\left(r_{m}-\pi-n\right) m\right] \\
& \quad+\lambda_{k}[i-(n+\delta) k]
\end{aligned}
$$

where the dependence of $H^{*}$ on $t$ enters through $A$ and $z$. The control variables are $c$ and $i$. The state variables are $m$ and $k$. The Pontryagin conditions are:

$$
\begin{aligned}
& \partial H^{*} / \partial c=u^{\prime}(c)-\lambda_{m}\left(1+G_{c}\right)=0 \\
& \partial H^{*} / \partial i=-\lambda_{m}\left(1+G_{i}\right)+\lambda_{k}=0 \\
& \rho \lambda_{m}-\partial H^{*} / \partial m=\left(\rho+n+\pi-r_{m}+G_{m}\right) \lambda_{m}=\lambda_{m} \\
& \rho \lambda_{k}-\partial H^{*} / \partial k=(\rho+n+\delta) \lambda_{k}-F_{k}\left(1-G_{y}\right) \lambda_{m}=\lambda_{k}
\end{aligned}
$$

In a steady state with $G_{c}$ constant and $\dot{c} / c=g,(\mathrm{~A} .1)$ and the constant elasticity of $u^{\prime}$ imply $\lambda_{m} / \lambda_{m}=-\sigma g$. This and (A.3) imply (7). With $G_{i}$ constant (A.2) implies $\lambda_{k} / \lambda_{k}=-\sigma g$. Using this and substituting for $\lambda_{m}$ in (A.4) using (A.2) produces (6).

The envelope result used in deriving (8) is:

$$
\int_{0}^{\infty} e^{-\rho t} u^{\prime}\left(c^{e}\right)\left(I+G_{c}\right)^{-1}\left[\left(1-G_{y}\right) F_{k} \partial k^{e} / \partial \pi-\left(1+G_{i}\right) \partial t^{e} / \partial \pi\right] d t=0
$$

From (A.1) and (A.2) the integral can be expressed as:

$$
\int_{0}^{\infty} e^{-\rho t}\left[\lambda_{m}\left(I-G_{y}\right) F_{k} \partial k^{e} / \partial \pi-\lambda_{k} \partial i^{e} / \partial \pi\right] d t
$$


From (2) this is:

$$
\int_{0}^{\infty} e^{-\rho t}\left\{\left[\lambda_{m}\left(I-G_{y}\right) F_{k}-\lambda_{k}(n+\delta)\right] \partial k^{e} \partial \pi-\lambda_{k} \partial k^{e} / \partial \pi\right) d t .
$$

From integration by parts and (A.4):

$$
\begin{aligned}
\int_{0}^{\infty} e^{-\rho t} \lambda_{k}\left(\partial k^{e} / \partial \pi\right) d t=\int_{0}^{\infty} e^{-\rho t}\left[\rho \lambda_{k}-\lambda_{k}\right] \frac{\partial k^{e}}{\partial \pi} d t & \\
& =\int_{0}^{\infty} e^{-\rho t}\left[F_{k}\left(1-G_{y}\right) \lambda_{m}-(n+\delta) \lambda_{k}\right] d t
\end{aligned}
$$

The last pair of equalities shows the integral to be evaluated vanishes.

To derive (11) rewrite (6") and ( $\left.7^{\prime \prime}\right)$ as:

$$
\begin{aligned}
& a\left(I-G_{y}(a, \lambda, \pi)\right)=\rho+\sigma g+n \\
& \quad-G_{m}(a, \lambda, \pi)=\rho+\sigma g+n+\pi-r_{m} .
\end{aligned}
$$

Therefore:

$$
\partial g / \partial \pi=a\left(G_{y m}+G_{m \pi} G_{y m}-G_{y \pi} G_{m m}\right) / \Delta,
$$

where:

$$
\Delta=\sigma\left(G_{m m}-a G_{y m}\right)
$$

By Euler's Theorem:

$$
\lambda G_{m m}+a G_{y m}=0
$$


Therefore:

$$
\partial g / \partial \pi=-\left(1+G_{m \pi}+(a / \lambda) G_{y \pi}\right) / \sigma(I+(1 / \lambda))
$$

which yields (11), since, by Euler's Theorem:

$$
\lambda G_{m \pi}+a G_{y \pi}=\partial\left(\lambda G_{m}+a G_{y}\right) / \partial \pi=\partial G / \partial \pi
$$

To derive (12), note that, from the facts cited just before (12):

$$
\begin{aligned}
& \partial U_{\partial} \partial \pi=\int_{0}^{\infty} e^{-\rho t}\left(c^{e}(0) e^{g t}\right)^{-\sigma^{g t}} e^{e}\left(\partial c^{e}(0) / \partial \pi+t c^{e}(0) \partial g / \partial \pi\right) d t
\end{aligned}
$$

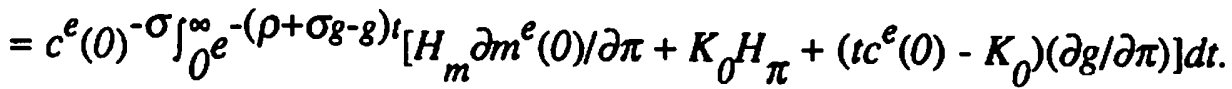

Since $c^{e}(0)^{-\sigma}=\lambda_{m}(0), H_{m}=r-r_{m}, K_{0} H_{\pi}=-G_{\pi}\left(a K_{0}, m^{e}(0), \pi\right)$, and $\rho+\sigma g-g=$ $r-\pi-n-g$; it is therefore sufficient to show that:

$$
\int_{0}^{\infty} e^{-(\rho+\sigma g-g) t}\left(t c^{e}(0)-K_{0}\right) d t=m^{e}(0)\left(r-r_{m}\right) /(\rho+\sigma g-g)^{2} .
$$

The integral on the left side equals:

$$
\left[K_{0} H(1, \lambda, \pi)-(n+g) K_{0}-(\rho+\sigma g-g) K_{0}\right] /(\rho+\sigma g-g)^{2},
$$

which, by Euler's Theorem equals:

$$
\left(H_{k} K_{0}+H_{m} m^{e}(0)-(n+\rho+\sigma g) K_{0}\right) /(\rho+\sigma g-g)^{2} .
$$

The desired equality follows from this, using (6") and ( $\left(7^{\prime \prime}\right)$. 


\section{Endnotes}

*Professor of Economics, Bank of Montreal Chair of Money and Finance, University of Western Ontario.

1Fischer and Huizinga (1982) analyze the results of this and other polls in the United States.

2"Mundell-Tobin" actually refers to two distinct effects, first presented by Mundell (1963) and Tobin (1965) respectively. Both involve a reduction in real balances caused by the effect of inflation on the opportunity cost of holding real balances. In both cases, smaller real balances encourage a higher propensity to save. For Mundell the encouragement takes the form of a wealth effect, whereas for Tobin it is an effect working through disposable income, one component of which is the annual increase in real balances. The effects appear to be quite similar quantitatively as well as theoretically.

${ }^{3}$ Note that the initial stock of real balances, although given to the family, is endogenous to the economic system.

${ }_{4}^{4}$ See Wallis and North for the estimate of $H$. Note that if labor is paid its marginal product then $(1-\alpha-\beta)$ will be approximately labor's share of GNP.

5The interest rate $r_{m}$ is included to clarify subsequent analysis, but has played no role so far. In the numerical analysis $r_{m}$ was assumed to be zero.

6By construction, $H_{m \pi} H_{k m} \cdot H_{k \pi} H_{m m}=F_{k}\left(G_{m y} G_{m \pi} \cdot G_{y \pi} G_{m m}\right)$. By Euler's Theorem, $G_{m y} G_{m \pi} \cdot G_{y \pi} G_{m m}=-G_{m m} G_{\pi} / y$.

7Similar welfare implications have been derived by Konieczny (1987).

${ }^{8}$ See, for example, Kleiman's (1989) account of Israel's experience.

${ }^{9}$ The flow of resources into transaction services is $G(F(k, A), m, \pi)$. The short-run effect of inflation on this flow is thus $G_{\pi}+G_{m} \partial m^{e}(0) / \partial \pi$, where $\partial m^{e}(0) / \partial \pi$ represents the impact effect of inflation, which can be shown to be negative. As long as the opportunity cost $r-r_{m}$ is 
positive then $G_{m}$ is negative.

10The condition: $\rho+\left[a\left(1-G_{y}\right)-n\right](\sigma-1)>0$ must hold for the family's objective function to be bounded. This will hold in the log case: $\sigma=1$.

11The Appendix derives (11). A negative effect of inflation on long-run growth was derived by Mitsui and Watanabe (1989) in the context of the Townsend turnpike model of money, which incorporates only the money-taxing aspect of inflation.

12See, for example, the discussion by Mehra and Prescott (1985, p. 154). The boundedness condition of footnote 10 above places a lower limit on $\sigma$ if $g>0$, but this limit depends on the unobservable $\rho$.

13Of course a more satisfactory analysis of research and development would have to deal with imperfect competition, for reasons known since Schumpeter. However, Romer (1990) has shown how an imperfectly competitive model can be developed with a similar formal structure to the one used in his earlier work.

14To derive (16) note that the derivative $\partial g / \partial r_{m}$ is the negative of what $\partial g / \partial \pi$ would be without the transaction-impeding aspect. From (11), this is: $\partial g / \partial r_{m}=\lambda / \sigma(1+\lambda)$. Adding this to (11) yields (16).

15Take any equilibrium with $\pi \in(0, \mu-n)$ and perturb the function $G$ so as to raise $G_{\pi}$ above $\sigma(1+\lambda)$ without altering the partial derivatives $G_{y}$ and $G_{m}$ at the equilibrium. 


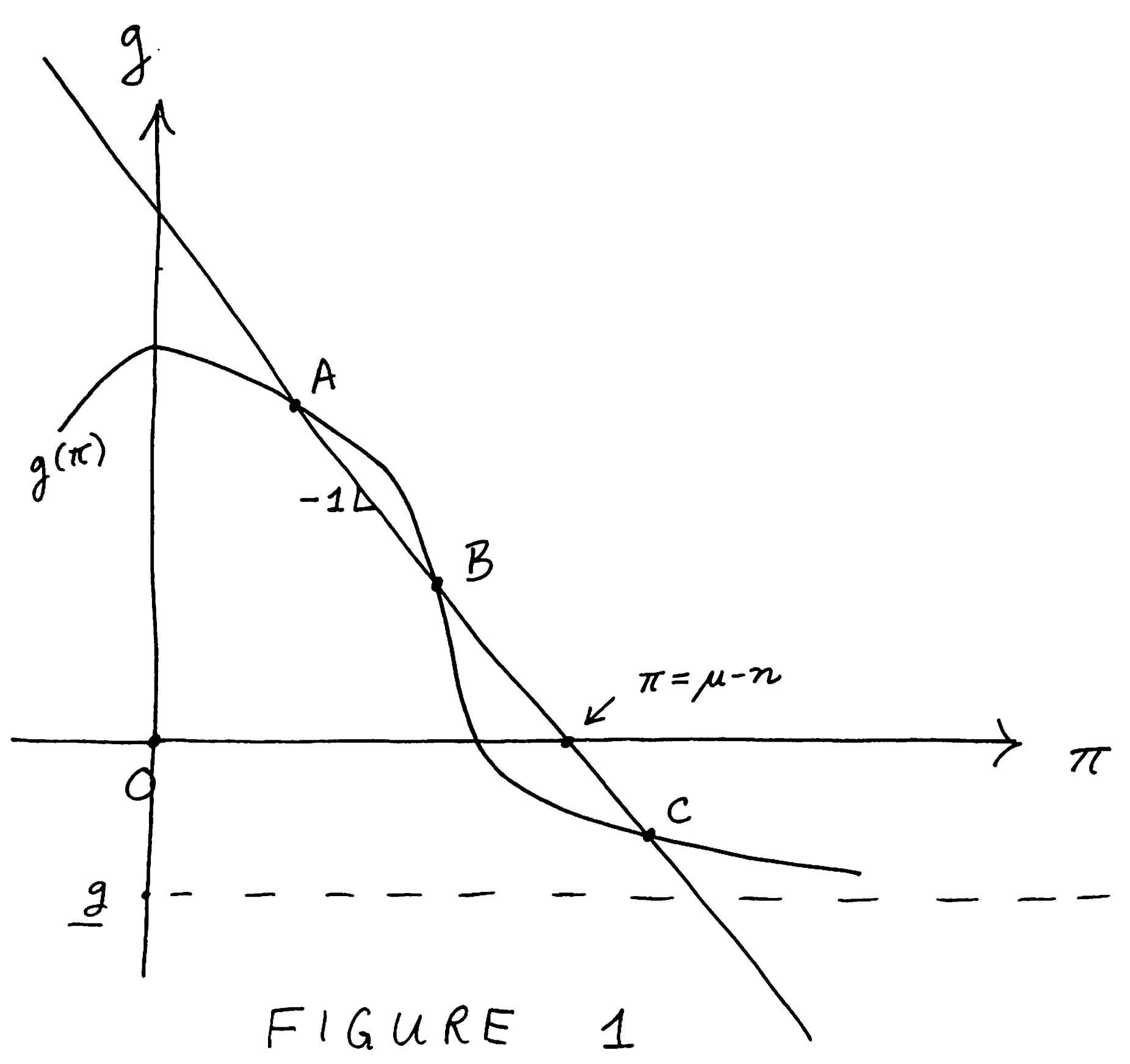

